\title{
O conservadorismo-liberal no Brasil de Bolsonaro: a força da articulação no contexto de pandemia
}

\author{
Sávio M. Cavalcante \\ Mariana Miggiolaro Chaguri \\ Michel Nicolau Netto
}

\begin{abstract}
Resumo
Neste artigo, apontamos que o governo do presidente Jair Bolsonaro está assentado numa articulação política e ideológica que chamamos de conservadorismo-liberal. Para explorar este argumento, nos detemos prioritariamente na análise da reunião ministerial realizada em abril de 2020, sustentando que a reconversão da pauta operada em seu curso e as opções realizadas para o enfrentamento da pandemia da Covid-19 por parte do governo federal nos permitem caracterizar os conteúdos próprios do conservadorismo-liberal. Abordamos, assim, temas como as noções de liberdade e o papel da família e do Estado na articulação entre esses dois polos.
\end{abstract}

\begin{abstract}
In this article, we point out that President Jair Bolsonaro's administration is settled on a political and ideological articulation that we call liberal-conservatism. To explore this argument, we primarily focus on the analysis of the ministerial meeting held in April 2020, sustaining that the reconversion of the agenda in that occasion, as well as the options taken by the federal government to face the Covid-19 pandemic, allow us to characterize the specific content of the liberalconservatism. Thus, we approach themes such as the notions of freedom and the role of family and of the State in this ideology.
\end{abstract}


Passados dois anos de sua posse, o governo de Jair Bolsonaro segue provocando e enfrentando sucessivas crises políticas e institucionais. A isso se somam altas taxas de desemprego, baixo crescimento econômico, além da maior crise sanitária da história do país, provocada, em especial, pela gestão federal da pandemia da Covid-19. Ainda assim, a aliança entre conservadores e neoliberais que esteve na base de sua eleição segue demonstrando estabilidade e resiliência política mesmo em um contexto, no mínimo, adverso. $\mathrm{O}$ que explica a aliança entre conservadores e neoliberais presente no governo do presidente Jair Bolsonaro? Quais são as bases e as forças sociais que a sustentam? Por que ela se mantém fortalecida a despeito da radicalização do governo e do agravamento da crise sanitária da pandemia da Covid-19?

Em outros trabalhos (Nicolau Netto, Cavalcante \& Chaguri, 2019), argumentamos que esta aliança entre conservadores e neoliberais não corresponde a uma mera sobreposição de ideologias ou a um encontro de ocasião. Ao contrário, estamos diante de uma articulação de práticas sociais e culturais, condutas políticas e ideias econômicas que mantêm referências ao neoliberalismo e ao conservadorismo. Ou seja, trata-se de um pacto social e político distinto, ao qual corresponde um modo próprio de conduzir um governo e as políticas de Estado, legitimando um processo de dominação que pressupõe a adesão mínima e simultânea aos polos neoliberal e conservador.

Neste artigo, nosso objetivo é mostrar que essa articulação se torna ainda mais explícita e orgânica no contexto dos efeitos da pandemia da Covid-19 no Brasil. Usaremos, como fio condutor da análise, as falas e posições expressas num evento com alta carga simbólica e política: a reunião ministerial de 22 de abril de 2020. Participaram desta reunião o presidente Jair Bolsonaro, o vice-presidente Hamilton Mourão e ministros de Estado, totalizando 25 autoridades presentes.

Inicialmente, a pauta da reunião tratava do lançamento do Plano Pró-Brasil, um projeto com desenho genérico que visava estimular a recuperação da economia no contexto de possível desaceleração provocada pela pandemia do Covid-19. O plano era de responsabilidade do então ministro chefe da Casa Civil (e atual Ministro da Defesa), general Braga Netto. Entre seus princípios gerais, estavam a geração de emprego e a recuperação da infraestrutura do país.

A reunião ganhou notoriedade pública após o então ministro da Justiça, Sérgio Moro, afirmar que, no curso da reunião, Jair Bolsonaro havia dado declarações que demonstrariam 
sua tentativa de interferência na Polícia Federal, o que levou o Supremo Tribunal Federal (STF) a autorizar a divulgação do vídeo da reunião, bem como da transcrição de suas falas.

Seja pela generalidade do plano, seja pela tensão entre Guedes e Braga Netto no que se referia ao papel do Estado no estímulo à recuperação econômica num cenário de crise; ou ainda pelas reações da sociedade e, em especial, do STF1, em relação à pandemia, a reunião fez emergir um conjunto amplo de formulações e reflexões que tinha por objetivo preservar o programa original de governo ante as pressões para fortalecimento do papel e da ação do Estado em decorrência da pandemia. Sugerimos, assim, que menos do que discutir o plano Pró-Brasil e em seu bojo medidas mitigadoras da crise sanitária, o andamento da reunião a transformou num debate da alta cúpula do governo sobre como encontrar maneiras de fortalecer ou reposicionar o programa conservador-liberal num cenário no qual debates sobre a retomada do papel do Estado e as políticas de desenvolvimento econômico e social no pós-pandemia passaram a se fazer presentes nas agendas políticas e econômicas em boa parte do mundo.

Este deslocamento fez com que os temas abordados ao longo de quase duas horas de discussões fossem os mais variados. No decorrer das falas, menos do que aproximações ou distanciamentos de posições nos polos neoliberal ou conservador, alguns dos membros mais proeminentes do governo Bolsonaro - o presidente incluído - apontam reiteradamente que um polo nunca anula o outro. Ao contrário, a unidade entre eles constituiria o centro de gravidade do bolsonarismo, numa tendência que pode ser encontrada também em outras declarações públicas do presidente e de seus ministros, ou num conjunto variado de atos de governo.

O próprio presidente, por exemplo, fez do conservadorismo seu berço, mas afirma constantemente sua adesão ao neoliberalismo. Por exemplo, em seu discurso na Assembleia Geral da ONU, realizado em 24 de setembro de 2019, talvez o mais bem elaborado que proferiu em seu mandato, são explicitadas simultaneamente posições que o aproximam dos polos conservador -"a ideologia se instalou no terreno da cultura, da educação e da mídia, dominando meios de comunicação, universidades e escolas [...] invadiu nossos lares para investir contra a célula mater de qualquer sociedade saudável, a família" (Bolsonaro, 2019)

\footnotetext{
${ }^{1}$ Desde abril de 2020, o STF tem assegurado aos governos estaduais e municipais competência para a adoção de medidas restritivas durante a pandemia da Covid-19, tais como suspensão ou restrição de atividades de ensino e religiosas, restrições ao comércio, às atividades culturais e à circulação de pessoas, por exemplo. Ao serem questionadas formalmente ou minadas na prática pelo governo federal, as decisões do tribunal têm estado no centro de uma crise federativa sem precedentes no pós-redemocratização (1988).
} 
- e do neoliberal: "o livre mercado, as concessões e as privatizações já se fazem presentes hoje no Brasil" (Bolsonaro, 2019).

O debate sobre os encontros e desencontros entre conservadorismo e neoliberalismo também já foi desenvolvido por análises relativas a países centrais em trabalhos como os de Melinda Cooper (2017) e Wendy Brown (2006; 2019). É certo que a articulação de conservadores e neoliberais também responde a dinâmicas e temporalidades específicas dos diferentes países, especialmente pelas diferenças em relação aos graus de realização de modelos de Estado de Bem-estar social. Porém, guardadas as devidas proporções, consideramos que o argumento se mostra igualmente explicativo para o caso brasileiro.

Essa simultaneidade, no entanto, tem se tornado objeto de controvérsias e disputas no debate público brasileiro, tomando frequentemente as linhas editoriais e as páginas da grande imprensa ${ }^{2}$. Parte daqueles que vocalizam o pensamento liberal em tais veículos argumenta que essa aliança seria produto, sobretudo, de oportunismo político e, quando estabelecida, configura uma deturpação do sentido verdadeiro de liberalismo, pois a defesa do programa econômico neoliberal, liderada pelo Ministro da Economia, Paulo Guedes, não poderia ser compatível com um projeto conservador que promove, especialmente no que se denomina de pauta moral e dos costumes, um ataque à diferença e à diversidade (em termos de raça, gênero e sexualidade), o que é compreendido menos como direitos sociais e mais como ataques aos direitos individuais fundamentais (DeBolle, 2020).

Ainda que promotor de reformas pró-mercado, o governo Bolsonaro faria parte de uma onda internacional de governos "iliberais" (Levitsky \& Ziblatt, 2018). No caso brasileiro, essa posição costuma entender a radicalidade do atual governo como uma resposta relativamente compreensível à crise política e econômica (marcada por casos de corrupção) desencadeada no fim do ciclo de governos petistas, especialmente a partir de 2013 e mais robusta em 2015 e 2016. Segundo o argumento, ao fomentar a crise econômica e a corrupção, os governos petistas teriam suscitado a descrença popular em relação ao sistema político-partidário e às instituições da democracia representativa liberal como um todo (Fonseca, 2021). Bolsonaro seria, então, a reação esperada, agora à direita, do "populismo": relação direta com o povo (massa), contornando os mediadores institucionais e de imprensa tradicionais, construção de inimigos internos e externos que teriam

\footnotetext{
2 Tomamos como grande imprensa veículos de abrangência nacional como os jornais Folha de São Paulo, O Globo, O Estado de São Paulo, Valor Econômico, além das mídias televisivas e de internet do grupo Globo.
} 
corrompido a nação e uma cultura política "atrasada", pouco aderente a valores da democracia liberal.

O que torna essas análises pouco explicativas da efetiva caracterização do governo diz respeito menos ao que afirmam e mais ao que ocultam: o impacto do reformismo, ainda que "fraco" e dentro da ordem institucional (Singer, 2012), promovido por políticas neodesenvolvimentistas dos governos petistas (Boito Jr., 2018). A aceleração do crescimento econômico até o começo da década de 2010 foi acompanhada de um conjunto significativo de políticas sociais que instauram não apenas um conflito distributivo entre classes e frações de classe, mas também um acirramento das tensões sobre as formas de poder que organizam historicamente a sociedade brasileira. Em uma sociedade profundamente desigual como a brasileira, erigida por uma sistema de classificação/desclassificação social de origem patriarcal/estamental, mesmo reformas limitadas provocam abalos significativos se promovidas em curto espaço de tempo.

Assim como o conservadorismo-liberal que caracteriza o governo Bolsonaro não dissocia a pauta de valores da econômica, as políticas do ciclo neodesenvolvimentista combinaram estratégias de redistribuição de renda com uma repercussão, de modo mais ou menos intenso, nas fontes de poder e dominação que garantiam a inércia da reprodução social. Este é o fundamento mais amplo de análise que informa a discussão a seguir.

No primeiro item, descrevemos e organizamos as principais intervenções dos participantes na referida reunião ministerial. No segundo item, partimos dessas falas para desenvolver de modo mais detalhado as razões que explicam a coesão e o alcance do conservadorismo-liberal no país. Por fim, indicamos que a política negacionista do governo Bolsonaro em relação à pandemia possui, entre suas fontes, justamente os valores do conservadorismo-liberal ${ }^{3}$.

\section{Uma reunião, a pandemia e o papel do Estado.}

Não há novidade em dizer que o governo Bolsonaro une conservadorismo e neoliberalismo. Isso é afirmado por seus próprios membros e não faltam análises que

\footnotetext{
${ }^{3}$ Optamos por usar o conceito sem o prefixo "neo" em liberalismo com o objetivo de acentuar que, do ponto de vista concreto, o neoliberalismo é o liberalismo realmente existente no Brasil. Um liberalismo "puro", dissociado de princípios neoliberais, não possui base social e eleitoral autônoma no país. Ademais, com essa opção, é possível acompanhar as disputas implicadas nos termos liberal e conservador e, sobretudo, possibilita acompanhar o movimento de vinculação ideológica que tais agentes visam produzir entre o momento atual e a suposta superioridade das democracias liberais e cristãs na cruzada em defesa do Ocidente contra o comunismo durante o período da Guerra Fria (1947 - 1991).
} 
convergem nesse mesmo diagnóstico (Lacerda, 2019). Contudo, isso geralmente é visto como a justaposição dos termos que, em si, podem ser separados. Eles apenas ocorrem de estar lado a lado nesse governo numa convivência circunstancial e não numa coalizão político-ideológica.

Como apontamos, a tese da justaposição está presente em linhas editoriais da maior parte da imprensa brasileira, e é central para a compartimentalização do próprio governo em núcleos: de um lado o ideológico, que formaria o campo conservador; de outro, o neoliberal. A esses núcleos correspondem agentes bem estabelecidos e inconfundíveis. No momento da reunião aqui analisada, em relação aos ministérios, isso significava: no primeiro, Damares Alves (Mulher, da Família e dos Direitos Humanos), Ernesto Araújo (Relações Exteriores), Abraham Weintraub (Educação) e Ricardo Salles (Meio-Ambiente); no segundo, Paulo Guedes (Economia), Sergio Moro (Justiça), Tarcísio de Freitas (Infraestrutura). Orbitando em torno desses grupos, estariam as pastas comandadas por militares, cuja caracterização - no começo de 2020 - oscilava entre o perfil supostamente técnico dos altos escalões das Forças Armadas e a desconfiança em relação aos compromissos com as instituições democráticas por parte desses mesmos atores 4 .

Da mesma forma, tais análises tendem a atribuir a esses núcleos um conjunto de significados que não se comunicariam, sejam em suas defesas ou em seus ataques. Ao primeiro núcleo são atribuídos termos como religião ou fanatismo; valores ou preconceito; loucura ou fé; irracionalidade ou moral. Ao segundo, os termos são outros: racionalidade ou insensibilidade; competência ou incompetência; sucesso ou insucesso. Ou seja, tudo se passa como se estivéssemos diante de um quadro de classificação em que tudo é oposto e incomunicável, mas está ocasionalmente junto. Um quadro no qual seus agentes se aturam, mas não se misturam. Isso se nota também pelo fato de que asseclas mediáticos dos dois núcleos são capazes de criticar o núcleo oposto e tentar salvar o seu, como se fossem peças que podem ser desencaixadas.

No entanto, a análise da reunião ministerial de 22 de abril de 2020 demonstra algo diferente. O que se nota ali não é a existência de dois núcleos com dificuldades de comunicação ou pouco intercambiáveis. Ao contrário, são inúmeros os posicionamentos e

\footnotetext{
${ }^{4}$ No momento da reunião, o governo brasileiro contava com cinco pastas ocupadas por militares da reserva (Casa Civil, Gabinete de Segurança Institucional, Ministério da Defesa, Secretaria de Governo e Ministério da Infraestrutura). A presença de militares, no entanto, não se limita ao comando das pastas. Atualmente, as estatais com participação da União possuem 92 militares em postos de comando. Segundo dados do Tribunal de Contas da União, em 2020, existiam 6.157 militares exercendo funções civis na administração pública federal (em 2016, ano do último levantamento, eram 2.957) (Seabra \& Garcia, 2021).
} 
as manifestações de uma ideologia que aqui denominamos de conservadorismo-liberal. $\mathrm{O}$ uso do hífen, no lugar de um "e", tem o sentido de demonstrar, graficamente, a junção entre os termos, o amálgama uma vez mencionado por Ernesto Araújo ${ }^{5}$.

No entanto, apontar a existência de uma só ideologia não significa afirmar que os membros desse governo não possuem diferenças. É bastante óbvio que suas formações, seus linguajares, suas posturas de voz e os termos que usam são bastante distintos. De fato, a linguagem de Bolsonaro é peculiar, marcada por palavrões - o presidente usa "porra", "puta", "putaria", "bosta" e "merda", em conjunto, 30 vezes - e por termos ligados ao uso da força - "forças armadas", "povo armado", "mundo armado", "armado", "armamento", "exército", "algema" são usados 17 vezes. Isso não se repete nos outros presentes, que adotam um jargão mais próximo de suas áreas e de suas vinculações a grupos sociais. Guedes, por exemplo, se porta como um professor, de fala contida e frequente uso de termos técnicos, com frequência alta para termos como economia ( 9 vezes), juros (8 vezes) e plano Marshall (10 vezes). Weintraub se porta como um missionário de uma causa e repete diversas vezes que se vê como um militante da liberdade; Damares Alves se apresenta como alguém que busca salvar almas, e repete 14 vezes o termo valores. Araújo fala pouco nessa reunião, mas repete sua forma de ver o mundo como um grande complô da esquerda oculto no termo de globalização, um de seus termos mais repetidos.

Contudo, por trás dessas diferenças, as falas convergem para a costura de ideias conservadoras e neoliberais. A linha dessa costura é dada por Bolsonaro quando afirma que suas "bandeiras" são: "família, Deus, Brasil, armamento, liberdade de expressão, livre mercado." E ameaça: "Quem não aceitar isso, está no governo errado." Podemos ordenar essas "bandeiras" nos seguintes termos: "família", "crença/valores/religião", "ordem mundial", "força" e "liberdade". Se assim o fizermos, podemos notar que todos eles, se declinando de formas variadas, aparecem em todos os discursos da reunião.

Antes de entrarmos na descrição e análise dos temas discutidos na reunião ministerial, é importante situar de forma mais ampla as ações do governo federal nessa conjuntura. Ao longo de 2019, Bolsonaro ampliou os poderes institucionais do Ministério da Economia. Ainda que distante da velocidade das mudanças exigidas pelo mercado financeiro, o programa neoliberal avançou em dimensões importantes, especialmente no campo da seguridade social (Reforma da Previdência em 2019) e no fortalecimento de

\footnotetext{
${ }^{5}$ Em palestra na Heritage Foundation, o então ministro afirmou: "Eu penso que estamos criando no Brasil um amálgama conservador-liberal" (Araújo, 2019, p.3).
} 
projetos liberalizantes que, em setembro de 2020, viabilizaram a aprovação da Lei da Liberdade Econômica ${ }^{6}$. As investidas em outras frentes, como no campo da cultura, educação e de políticas sociais, eram marcadas pela orientação conservadora de ministérios e secretarias comprometidos com o que era entendido como preservação dos valores e da família ${ }^{7}$.

A chegada da pandemia ao país provoca um grande abalo nesse projeto. As medidas de isolamento e restrição de circulação de pessoas, preconizadas como fundamentais para controle epidemiológico, acarretariam uma inevitável queda da atividade econômica. Os estados da federação, desde março, exigiam aumento de repasse de verbas para ampliar o sistema de saúde e saldar compromissos dado o risco com a queda das receitas. No início de abril de 2020, em decorrência da pressão de movimentos sociais e parte do Congresso Nacional, o governo federal começa a estabelecer um programa de auxílio emergencial para as milhões de pessoas cuja renda é drasticamente afetada pela diminuição da atividade econômica na pandemia. De maneira geral - não apenas no Brasil, mas na maior parte do mundo - a política neoliberal é vista como potencialmente incapaz de dar conta de um desafio sanitário que exige priorizar, para ser contido, a dimensão coletiva em detrimento de interesses individuais.

Em meio às pressões políticas e sanitárias, a linha de ação do governo federal já havia sido apresentada em suas bases fundamentais em 24 de março de 2020, por meio de pronunciamento do presidente em cadeia nacional de rádio e televisão. Valendo-se de uma retórica de líder militar, o presidente comparou a Covid-19 a uma "gripezinha ou um resfriadinho", que "brevemente passará", e diagnosticou uma patologia alternativa: a crise econômica e o caos social que seriam causados pelo "pânico e histeria", especialmente da oposição e de meios de comunicação que não teriam como fundamento "o equilíbrio e a verdade" (Bolsonaro, 2020) ${ }^{8}$.

\footnotetext{
${ }^{6}$ Em linhas gerais, a legislação visa reduzir a burocracia nas atividades econômicas, com a flexibilização da legislação trabalhista e limitação da capacidade fiscalizadora do Estado. Ao sancionar a nova lei, Bolsonaro declarou que se tratava de "mais um passo para tirar o estado do cangote de quem trabalha e produz (geração de empregos e economia)" (Paranhos, 2019).

${ }^{7}$ Entre os vários exemplos disponíveis, recortamos aqui a atuação da ministra Damares Alves. É em cooperação com sua pasta, por exemplo, que o Itamaraty apresentou a cartilha de candidatura brasileira ao conselho de Direitos Humanos da ONU, em 2019, na qual o Brasil prometeu "fortalecer os vínculos familiares" além de "apoiar iniciativas que contribuam para fortalecer as estruturas e relações familiares" (Alves, 2019 citado em Chade, 2019).

8 Para uma análise de como o conservadorismo-liberal é instrumentalizado por um movimento e uma ideologia neofascistas, especialmente na condução da pandemia, ver Cavalcante (2021).
} 
Essa posição, contudo, não foi integralmente absorvida por Henrique Mandetta, então Ministro da Saúde. Ao identificar em Mandetta resistências à linha adotada pelo governo federal, abertamente contrário a medidas amplas de isolamento social, Bolsonaro demite o ministro em 16 de abril, substituindo-o por Nelson Teich que, por sua vez, ficaria menos de trinta dias no cargo, até ser substituído pelo general da ativa Eduardo Pazuello.

É este o pano de fundo mais amplo que marca a elaboração - e o anúncio - do Plano Pró-Brasil, objeto de apresentação e discussão na reunião ministerial. Àquela altura, o governo federal já havia delimitado sua estratégia de enfrentamento à pandemia e ela limitava-se à não alteração da rota dos programas e planos em prática desde 2019.

A reunião iniciou-se com uma exposição rápida de Braga Netto, na qual se destaca o que o ministro denomina de "medidas estruturantes": "arcabouço normativo, investimentos privados, segurança jurídica, produtividade, melhoria no ambiente de negócios e mitigação dos impactos socioeconômicos" (Braga Netto, 2020).

Guedes é o primeiro a tomar a palavra após a apresentação de Braga Netto. De início, adverte os presentes para evitar o termo, Plano Marshall, que estava sendo usado pela imprensa para designar o projeto. O cuidado revela o receio em dissociar o plano de qualquer princípio associado a políticas desenvolvimentistas. Reforça, na sequência, que as reformas pró-mercado são o único caminho para reconstrução estrutural do país. A crise pré-pandemia seria produto de 30 anos de governos "socialdemocratas" que teriam aumentado o endividamento do Estado e inibido o investimento privado. A pandemia não poderia mudar esse rumo (Guedes, 2020).

O único, e mesmo assim parcial, contraponto proferido ao longo de toda a reunião veio na sequência, na fala de Rogério Marinho, Ministro do Desenvolvimento Regional. Marinho não divergia dos pressupostos neoliberais, mas considerou que a crise promoveria um impacto muito maior do que se estava imaginando, a ponto de fazer com que governos liberais, ainda mais fortes em outros países, também viessem a aumentar significativamente o endividamento. Era preciso, portanto, "reduzir a mortandade de empresas" (Marinho, 2020, p.18), levando em consideração que a régua do endividamento mundial seria necessariamente alterada.

Feito o parcial contraponto, Onyx Lorenzoni, Ministro da Secretaria-Geral da Presidência, retomou a posição de Guedes ao indicar que a direção não poderia ser distinta daquela que estava sendo pavimentada pela Lei da Liberdade Econômica. A referência seria o modelo historicamente dominante nos EUA, visto como avesso ao intervencionismo. Esta 
postura é reforçada, com alguns acréscimos dignos de nota, nas intervenções de Ricardo Salles (Meio-ambiente) e Roberto Campos Neto, presidente do Banco Central.

Baseado numa lógica comum no meio empresarial, Salles argumenta que, em vez de crise, a pandemia traria uma grande oportunidade de acelerar reformas que favoreceriam o investimento privado e a previsibilidade dos negócios. A lógica era de que a atenção de órgãos do Estado e da imprensa voltada à pandemia faria com que "mudanças infralegais" recebessem menos destaque na pauta nacional. A expressão que usou na ocasião - seria a oportunidade de "passar a boiada" - recebeu forte destaque crítico quando da divulgação do vídeo da reunião, pois seria prova das ações deliberadas do governo no intuito de derrubar medidas legais de proteção ao meio-ambiente. Menos destaque, contudo, foi dado ao contexto de sua enunciação: a frase resumia o espírito da reunião como um todo, a saber, de preservação da liberdade econômica e dos direitos de propriedade. "Passar a boiada" (Salles, 2020, p.20) é formulado no interior do discurso geral que visava ampliar a liberdade de negócios, simplificar burocracia e, assim, aumentar a confiança dos investidores.

O presidente do Banco do Brasil, Roberto Campos Neto, por seu turno, retoma o raciocínio de Guedes ao observar que os gastos realizados para lidar com a pandemia teriam como risco serem feitos "a fundo perdido" e sem efeito "multiplicador", algo que comprometeria um cenário de contas públicas saudáveis para o investidor. O desafio seria identificar exatamente, via monitoramento dos recursos, o quanto desse gasto seria recuperado no futuro por meio da preservação de emprego e por "manter viva uma empresa que ia morrer" (Campos Neto, 2020, p.43).

Porém, o que chama ainda mais a atenção é a análise que Campos Neto realiza sobre a insuficiência da manutenção das atividades econômicas. Poderia ser feito um esforço para manter comércio e estádios abertos, mas as pessoas, especialmente as mais ricas, continuariam com medo de frequentar esses espaços:

e o fator medo é interessante porque, quanto mais informação você tem, mais medo você tem, porque a mídia joga medo. Então, você tem hoje uma classe mais alta que tem mais medo que a classe mais baixa, exatamente porque eles têm mais acesso à informação; e a informação é enviesada. Então, o primeiro ponto é esse de tomar risco (Campos Neto, 2020, p.43).

Essa dimensão da fala de Campos Neto é importante no sentido de compreender as diversas fontes que confluíram na estratégia federal de minimizar os efeitos sanitários da 
pandemia. Veremos, na sequência, como essa abordagem neoliberal é preenchida com uma base ideológica ainda mais forte, propiciada pelos ministros mais ancorados na linha conservadora.

As intervenções de Bolsonaro são recorrentes ao longo das falas e, nesse momento, torna-se mais explícita a pressão advinda dos interesses econômicos. Segundo o presidente, empresários estariam procurando o governo a todo o momento, e a posição não poderia ser diferente daquela de forçar a reabertura do comércio. A força do Estado aqui, aspecto primordial presente nas obras de referências máximas do neoliberalismo (Friedman, 1962; Hayek, 2011), aparece no sentido de garantir a preservação dos contratos e a liberdade de ação dos indivíduos-proprietários no mercado. Liberdade, enfim, é a liberdade irrestrita de poder sobre a propriedade privada.

Bolsonaro, então, exemplifica como a força do Estado precisa ser reorientada: ela estaria sendo usada para impedir obras em razão de legislação do Instituto do Patrimônio Histórico e Artístico Nacional (IPHAN) ("param a obra se acham um cocô de índio petrificado" - Bolsonaro, 2020b, p.27) ou para prender e algemar pessoas que desrespeitam as medidas de isolamento. Bolsonaro cobra maior comprometimento dos ministros e exige que defendam o governo nessas investidas.

Tem que ser um governo com altivez. Se expor, mostrar que nós temos o povo do nosso lado. Que nós somos submissos ao povo. nós queremos realmente, como disse, se não me engano Margareth Thatcher, né? Ou Reagan, não sei? (..) tem que ser conduzido pelo povo brasileiro, e ponto final. Onde o povo tá, vamos estar junto (...) E vamos solucionar, porque o destino do Brasil tá na mão desse grupo privilegiado que tá aqui. E eu não seria nada sem vocês (Bolsonaro, 2020b, p.28).

Esse conjunto de reações e declarações durante a reunião demonstram que o projeto neoliberal do governo Bolsonaro não deveria ser abandonado em função da pandemia ou do Plano Pró-Brasil. Ao contrário, o que se observa é a defesa desse projeto, mas na sua versão de fato existente no bolsonarismo, a versão do conservadorismo-liberal.

A restrição à livre circulação de pessoas emerge, então, com um dos temas a articular neoliberais e conservadores, mobilizando a atenção de boa parte dos presentes. Por exemplo, Damares Alves sustenta que tais medidas representariam a "maior violação de direitos humanos da história do Brasil [...] A pandemia vai passar, mas governadores e 
prefeitos responderão processos e nós vamos pedir inclusive a prisão de governadores e prefeitos" (Alves, 2020, p.47).

Ao associar tal restrição à mais grave violação dos Direitos Humanos da história do país, a ministra sustenta que todas as ações e políticas de enfrentamento à pandemia deveriam ser norteadas pelos valores do governo Bolsonaro, ou seja, era importante que os ministros não perdessem "o foco" para a "questão de valores". Dialogando com o ministro Braga Netto, Damares Alves afirma que "esse governo tem o pilar dos valores. Não se pode construir nada neste governo sem a gente trazer valores" (Alves, 2020, p.44). Pouco depois, a ministra se dirige a Teich e diz ao ministro recém-chegado: "quero te lembrar ministro, que tá chegando agora, este governo é um governo pró-vida, um governo pró-família" (Alves, 2020, p.46).

Ao chamar a atenção do ministro, Damares Alves procura enquadrar o novato, apontando que medidas não condizentes com tais valores não poderiam ser tomadas, ou seja, um governo pró-vida estaria comprometido, por exemplo, com a limitação dos direitos reprodutivos de mulheres, em qualquer cenário: "mulheres que são vítimas do zika vírus vão abortar, e agora vem do coronavírus? Será que vão querer liberar que todos que tiveram coronavírus poderão abortar no Brasil? Vão liberar geral?" (Alves, 2020, p.46).

O alerta da ministra para que, independentemente da crise, os presentes não perdessem o foco nos valores como elemento definidor do governo Bolsonaro parece ressoar e é retomado por diferentes interlocutores, se dirigindo diretamente a ela ou não. Entre tais valores, o da liberdade é o mais mobilizado, posto ser o valor que estaria mais fortemente ameaçado num contexto no qual as políticas de isolamento social fizeram ressoar de modo ainda mais forte e constante a retórica de que as liberdades - de empresas, famílias e indivíduos - estariam sob forte ataque.

Desse modo, uma reunião inicialmente voltada para tratar sobre planos de recuperação econômica converte-se num fórum de debates sobre como caracterizar e como reagir aos ataques à liberdade que estariam em curso no país, bem como sua associação com desafios mais amplos do governo no plano internacional e na disputa moral dos valores gerais da sociedade brasileira. Progressivamente, seja na recusa velada aos projetos de recuperação econômica do Plano Pró-Brasil, seja no enfrentamento aberto às medidas de isolamento social tomadas por governadores e prefeitos, o tema da liberdade parece sintetizar o conflito político e ideológico no qual o governo estaria imerso. 


\section{Liberdade, nação, família e o conservadorismo-liberal.}

Como visto até aqui, ainda que a noção de liberdade mobilizada por tais atores remonte à clássica oposição do liberalismo entre indivíduo e sociedade, e entre mercado e Estado, a noção torna-se elástica no amálgama do conservadorismo-liberal. Se, no liberalismo, o indivíduo-proprietário é a unidade social mínima que deve se sobrepor a todas as outras instâncias sociais, no conservadorismo-liberal, este passa a ser necessariamente acompanhado pela família, a rigor, um modelo específico de família. São, portanto, os valores associados a este indivíduo entendido como família que passam a organizar o núcleo duro do conservadorismo liberal. A liberdade individual típica do liberalismo é reinterpretada e convertida na liberdade da família tanto para orientar sua conduta pública a partir de valores da domesticidade e de seu universo de relações privadas, quanto para proteger e cuidar de suas propriedades (sejam elas terra, imóveis, pequenas ou grandes empresas).

A articulação entre conservadorismo e neoliberalismo demanda um ajuste ideológico - que tem no governo Bolsonaro um dos principais representantes no mundo - que valorize duas dimensões: 1) um refinamento semântico do que se entende por liberdade, para que nele caiba tanto valores propriamente liberais, quanto conservadores, possibilitando que um legitime o outro; 2) uma noção de povo, valores e nação que permita a "universalização" de uma ideologia correspondente a esse sentido de liberdade.

No contexto das medidas de isolamento social, o povo, a nação e seus valores estariam sob ataque, constrangidos pelos limites de decretos de governadores e prefeitos, mas também pelas amarras impostas por agências multilaterais como a Organização Mundial de Saúde (OMS) e os interesses do chamado globalismo.

O tema da liberdade é historicamente caro ao neoliberalismo. É ele que estaria mais fortemente ameaçado pela exigência de uma intervenção do Estado na economia e nas políticas de restrição de circulação das pessoas. Ocorre que a noção de liberdade mobilizada pelos neoliberais precisa de uma justificação. E ela não pode ser apenas econômica, mas moral. Se Guedes fala em liberdade como princípio econômico, Weintraub, Damares Alves e Ernesto Araújo a qualificam em termos de valores. A fala de Araújo na reunião é a mais elucidativa desse ponto. Segundo o ex-ministro:

Que que aconteceu nesses trinta anos [desde o fim da guerra-fria]? Foi uma globalização cega para o tema dos valores, para o tema da democracia, da 
liberdade. Foi uma globalização que, a gente tá vendo agora, criou é ... um modelo onde no centro da economia internacional está um país que não é democrático, que não respeita direitos humanos etc., né? É ... essa nova globalização acho que não pode ser cega, né? É, tem que ser uma globalização, tem que ser uma estrutura, é, que leva em conta, claro, a dimensão econômica, mas também essa dimensão da, da liberdade, dos valores. Eé, da mesma maneira, acho que o plano e, tá apontando pra isso, no nosso e, é a nossa dimensão nacional, também não pode ser um plano cego para, a, essas dimensões do, daquilo que nos traz, né? Que traz o projeto do, do presidente, que é não simplesmente a eficiência, a pujança, o crescimento econômico, mas, ... liberdade, ... o combate a corrupção, a reinvenção de um Brasil, é ... livre, de um Brasil livre dessas, é... mazelas que nós conhecemos (Araújo, 2020, p.41).

Ou seja, a liberdade econômica é justificada apenas se acompanhada por uma noção de liberdade baseada em valores. Esses valores não são aqui explicitamente expostos, mas podem ser encontrados em tantos outros discursos de Araújo e podem ser traduzidos pela tríade Deus, nação e família. Para Araújo, as sociedades ocidentais não teriam reconhecido que a vitória sobre os países comunistas se deu em função de uma vinculação ocidental ao cristianismo, que permitiu que se lutassem contra os valores pagãos dos comunistas, pessoas, como afirma Araújo emprestando o termo de Marcuse, unidimensionais, justamente porque não possuem a dimensão simbólica produzida pela religião.

Em vez de reconhecerem o papel do cristianismo nessa vitória, os ocidentais "resolveram expulsar Deus do coração da sociedade liberal e deixaram Deus do lado de fora, ali no frio" (Araújo, 2019b). Isso teria significado uma restrição às condições de expressão da própria religiosidade cristã. Teríamos passado a viver "em um mundo onde falar dos heróis, dos ancestrais, da alma e da nação, da família e de Deus é, para grande parte da ideologia dominante, uma indicação de comportamento fascista" (Araújo, 2019b).

Enquanto isso, contudo, as próprias democracias liberais, especialmente pelas políticas multiculturalistas, passaram a defender outras formas de religião, como as afrobrasileiras, o islamismo, etc. Araújo entende, assim, que ao menos do ponto de vista das ideias, o cristianismo é atualmente vítima de perseguição no mundo. Isso significa que lutar pela liberdade é uma forma de lutar pela liberdade de se viver de acordo com o cristianismo, inclusive na política. Da mesma forma, liberdade é usada como forma de se contrapor ao que Araújo chama de globalismo. Segundo o Assessor Especial para Assuntos Internacionais do Presidente da República, Filipe G. Martins, 
globalismo é a tentativa de instrumentalização política-ideológica da globalização, com a finalidade de promover uma transferência do poder decisória das nações para um corpo difuso de burocratas, cosmopolitas e apátridas, que respondem não às comunidades nacionais de eleitores, mas a um restrito conjunto de agentes de influência com acesso privilegiado a esses burocratas, o que no limite significa a substituição das democracias liberais representativas por um regime tecnocrático e pouco transparente no qual o poder decisório está concentrado nas mãos de poucos privilegiados (Martins, 2019).

Isso significa que o globalismo é o oposto do nacionalismo, com o qual enfrenta o que Martins chama de "o grande confronto". A liberdade é aqui, então, mobilizada pela precedência da nação sobre os organismos internacionais. Isso porque, segundo pensa Araújo, tais organismos, como ONU, Organização das Nações Unidas para a Educação, a Ciência e a Cultura (UNESCO), Organização Mundial do Comércio (OMC), são dominados por um "momento em que o comunismo, o fisiologismo, o gramscismo, como quer que se chame, ocupa o coração que tinha sido deixado vazio da sociedade liberal" (Martins, 2019). Dominado por uma ideologia transnacional, que se manifesta, como fala Araújo em termos, "como direitos humanos, como tolerância, como a proteção ambiental, por exemplo" (Martins, 2019), os povos nacionais perdem a liberdade de expressar seus verdadeiros caracteres.

Como consequência, seria papel de um governo libertar os povos de uma nação dessa dominação internacional. Para Araújo, isso permitiria, no caso do Brasil, a legitimidade de um governo que se baseie em valores conservadores, em especial no que se refere à religião, à família, à sexualidade e às relações de gênero. Afinal, Araújo está convicto que assim é o povo brasileiro.

É, então, nas palavras do ex-ministro da Educação que vemos como, de fato, liberdade é um termo próprio do conservadorismo-liberal (ou seja, um termo novo, nem propriamente conservador, nem propriamente liberal) e ligada ao povo. Weintraub se preocupa com o plano Brasil uma vez que ele entende que o governo está se desviando de seu projeto. Ele alerta que:

A gente tá perdendo a luta pela liberdade. É isso que o povo tá gritando. Não tá gritando pra ter mais Estado, pra ter mais projetos, pra ter mais . . o povo tá gritando por liberdade, ponto. Eu acho que é isso que a gente tá perdendo, tá perdendo mesmo. A gen[te] ... O povo tá querendo ver o que me trouxe até aqui (Weintraub, 2020, p.53). 
No conservadorismo-liberal, a liberdade unifica duas recusas: a intervenção do Estado na economia e sua atuação na normatização de princípios universalistas para a cidadania. Cabe ao Estado, portanto, garantir a livre iniciativa dos indivíduos e das famílias, protegendo o direito de propriedade e garantido a prevalência dos valores da maioria nacional face a legislações, normas ou garantias constitucionais notadamente associados à democracia, à igualdade perante à lei ou mesmo ao direito à diferença com a consequente proteção de minorias culturais, religiosas ou étnicas.

Não por acaso, "povo" é um dos termos mais usados pelos presentes na reunião ministerial, a despeito dos supostos núcleos aos quais pertenceriam. Povo é a unidade semântica preenchida pelos valores baseados na família e na religião, e que se define pela nação. Contudo, ele ocupa uma função na ideologia conservadora-liberal. O povo é sempre definido como nacional. Em verdade, nada mais contrário a essa ideologia do que uma noção de cidadão mundial. Uma vez definido como nacional, esse povo é sempre universalizável, ou seja, aquilo que o caracteriza simultaneamente caracteriza todas as pessoas que pertencem a uma nação. O brasileiro, então, pode ser definido por termos simples: ele é cristão, conservador etc. A esses termos, todos os brasileiros devem se adequar. E sobre esses parâmetros que todos devem limitar suas diferenças. É nesse sentido que Weintraub afirma que

o termo "povos indígenas", odeio esse termo. Odeio. O "povo cigano". Só tem um povo nesse país. Quer, quer. Não quer, sai de ré. É povo brasileiro, só tem um povo. Pode ser preto, pode ser branco, pode ser japonês, pode ser descendente de índio, mas tem que ser brasileiro, pô! Acabar com esse negócio de povos e privilégios. Só pode ter um povo (Weintraub, 2020, p.54).

Figura política de ponta do bolsonarismo, o ex-ministro afirma estar no governo para não se tornar "escravo nesse país", uma escravidão que estaria associada à capital, Brasília, que, na qualidade de sede das instituições da República, era "um cancro de corrupção, de privilégio" e que os membros do governo não estariam "sendo duro(s) o bastante contra os privilégios, com o tamanho do Estado". No alerta de Weintraub, os presentes à reunião não podiam perder de vista que o povo brasileiro estaria gritando pela liberdade e não "pra ter mais Estado, pra ter mais projetos, pra ter mais ... o povo tá gritando por liberdade, ponto". Posição que, note-se, é acompanhada por Bolsonaro. 
Deixa eu complementar aqui. O que o Weintraub tá falando - eu tô com sessenta e cinco anos - a gente vai se aproximando de quem não deve. Eu já tenho que me policiar no tocante a isso daí. São pessoas aqui em Brasília, dos três poderes, que não sabem o que é povo. Esqueceu [..] Nós não podemos esquecer o que é esse povo (Bolsonaro, 2020b, p.55).

É, então, pela mobilização do termo povo - aliado à família, nação e Deus - que o conservadorismo-liberal adquire a sua legitimidade de não estar falando para um grupo específico (sejam os interessados no neoliberalismo, sejam os interessados na pauta conservadora), mas para um universo amplo definido pela nação.

Como visto, no contexto das medidas de isolamento social, o povo estaria sob ataque, constrangido pelos limites de decretos de governadores e prefeitos, mas também pelas amarras impostas por agências multilaterais como a OMS e os interesses do chamado globalismo. Dialogando com Weintraub, Bolsonaro sustenta que tais agentes queriam justamente "a nossa liberdade", ou seja, os limites à livre circulação de pessoas impostos pelas medidas de isolamento social, necessárias para a contenção da pandemia, tornam-se sinônimo de imposição de uma ditadura. Segundo o presidente:

Olha, eu tô, como é fácil impor uma ditadura no Brasil. Como é fácil. O povo tá dentro de casa. Por isso que eu quero, ministro da Justiça e ministro da Defesa, que o povo se arme! Que é a garantia que não vai ter um filho da puta aparecer pra impor uma ditadura aqui! Que é fácil impor uma ditadura! Facílimo! Um bosta de um prefeito faz um bosta de um decreto, algema, e deixa todo mundo dentro de casa. Se tivesse armado, ia pra rua. [...] Por que que eu tô armando o povo? Porque eu não quero uma ditadura! (Bolsonaro, 2020b, p.57).

A liberdade de indivíduos, famílias e empresas torna-se um coeso bloco de valores nacionais que não comportam qualquer ingerência do Estado, mesmo que esta seja decisiva para garantir a vida da população. Medidas como compra de vacinas ou renda básica, por exemplo, tornam-se atentados aos valores nacionais e são recusados de modo autoritário. A noção de liberdade que emerge do conservadorismo-liberal pode ser entendida, assim, como autonomia da maioria nacional para impor - de modo mais ou menos autoritários valores e normas de conduta gestados sobretudo na esfera privada, no interior de uma 
domesticidade que garante lugares e papéis sociais rigidamente definidos para as diferenças de raça e etnicidade, de gênero, de sexualidade e de classe.

A prevalência do sentido de liberdade tal como definido pelo conservadorismoliberal é tão marcante que, ao longo de toda a reunião, os termos "vida" e "morte" (e suas derivações) não são enunciados, como poderia se esperar num contexto de crise sanitária, num registro de significação vinculado aos riscos iminentes ao quais as pessoas como um todo estariam expostas pela Covid-19.

O termo "vida", sem contar as vezes que integra locuções como "feliz da vida" (Guedes) e "OAB da vida" (Bolsonaro), é enunciado apenas quatro vezes. E somente uma vez está vinculado aos riscos da doença, no momento em que o então ministro do Turismo, Marcelo A. Antônio, sugere um programa de disponibilização de quartos de hotel a profissionais de saúde. As outras três vezes são: na fala de Sergio Moro a respeito da necessidade de inclusão dos termos "segurança pública" e "corrupção" no projeto Pró-Brasil, como políticas que protegeriam a vida das pessoas; na fala de Damares Alves, já citada, para preservar o valor de governo "pró-vida" contra o aborto e, finalmente, de Bolsonaro ao advertir que "mais importante que a vida de cada um de vocês [ministros], (..) é a liberdade" (Bolsonaro, 2020b, p.58).

Quanto ao termo morte e suas derivações (incluindo "óbito"), há 11 referências que podem ser agrupadas em quatro grupos. No primeiro, os sujeitos que correm o risco de morrer são as empresas. Rogério Marinho e Roberto Campos indicam a necessidade de diminuir a "mortandade" de empresas. No segundo grupo, estão as referências à morte em razão dos movimentos de oposição ao governo. Weintraub relata "ameaças de morte" que teria recebido nas universidades; Pedro Guimarães (presidente da Caixa Econômica Federal) observa que "iria morrer" se a família fosse presa e algemada por não cumprir medidas de isolamento"; e Bolsonaro alerta que todos ali estariam "no mesmo barco" a ponto de, se houver problemas, " todo mundo [ir] pro saco aqui, vai todo mundo morrer afogado" (Bolsonaro, 2020b, p.26).

O terceiro grupo, com 3 citações, é composto, enfim, pelo sentido de morte provocado pela doença, mas num registro positivo: os índices de mortalidade seriam "bons" se comparados à média internacional ou estariam baixos e/ou diminuindo (Nelson Teich,

\footnotetext{
${ }^{9}$ Guimarães afirmou: "Eu já falei pra minha esposa: se tiver qualquer coisa, vou tomar um litro de hidroxicloriquina, aquelas coisas todas" (Guimarães, 2020, p.39).
} 
Damares Alves e Rubem Novaes ${ }^{10}$, então presidente do Banco do Brasil). O quarto e último grupo também faz referência às mortes provocadas pela doença, mas, agora, no sentido de ressaltar o uso político da pandemia. Pedro Guimarães observa como poucas mortes (de pessoas "já aposentadas e com mais de 70 anos") aparecem com ênfase nos jornais e Bolsonaro cita dois casos vistos como "deturpações": a morte de um sargento do exército por Covid "sem a indicação se ele tinha comorbidades" e "a bosta de um prefeito de Manaus que abriu covas coletivas. Uma bosta".

\section{Conclusão: o conservadorismo-liberal entre a democracia e o autoritarismo.}

Em linhas gerais, podemos definir o conflito material e ideológico do conservadorismo-liberal como expressão de uma disputa que abarca desde a organização dos modos de vida, em suas dinâmicas mais cotidianas, à regulação da economia, passa pelo esforço de rearranjo institucional das democracias liberais e visa redefinir valores e princípios que orientam o mundo contemporâneo. Sua emergência impõe, portanto, desafios às bases pretensamente universalistas da democracia liberal, comportando ataques sistemáticos e contínuos a princípios, normas, condutas e corpos - individuais ou coletivos - distantes dos conteúdos definidores da maioria nacional.

Como indicamos a partir dos debates realizados pela alta cúpula do governo federal na reunião ministerial de abril de 2020, a deflagração da pandemia de Covid-19 representou, para o campo conservador-liberal no poder, uma ameaça maior que a crise sanitária: uma crise política e ideológica que poderia comprometer a continuidade das reformas neoliberais e dos valores mais amplos que fornecem coesão ao bloco.

É importante destacar que, tanto do ponto de vista neoliberal quanto do ponto de vista conservador, não há defesa de um "Estado mínimo" (Dardot \& Laval, 2016). Nos dois casos e, principalmente, na articulação desses campos, o que se impõe é uma investida a respeito do conteúdo e da orientação da ação do Estado, que pode ser maior ou menor de acordo com as áreas e conjunturas. Ou seja, a ampliação do Estado (em termos, por exemplo, de segurança pública ou políticas públicas conservadoras em cultura e educação) não é a ameaça em si, mas uma crise de legitimidade do princípio moral (de valores) do conservadorismo-liberal, o qual se mostra incompatível com as exigências coletivistas das

\footnotetext{
${ }^{10}$ Em 25 de março de 2020, em mensagem a um grupo de WhatsApp, Novaes afirmou que a vida não tem "valor infinito" e que "muita bobagem é feita e dita, inclusive por economistas, por julgarem que a vida tem valor infinito". O vírus tem que ser balanceado com a atividade econômica" (Serapião, Serto, 2020).
} 
medidas epidemiológicas necessárias para conter os danos da pandemia. Dito de outro modo, essas medidas epidemiológicas seriam, de fato, impossíveis de serem praticadas se a sociedade fosse vista como uma simples soma de indivíduos-proprietários e suas famílias, o ponto de convergência do conservadorismo-liberal.

Por fim, é preciso destacar, novamente, como cada campo contribui para a formação do amálgama conservador-liberal. A radicalidade do programa neoliberal de reformas, ao transferir integralmente para as famílias a responsabilidade da seguridade social, precisa encontrar uma base de valores que fortaleça a instituição familiar. É o campo conservador, com uma fundamentação religiosa para a família e para a nação, que preenche esse espaço moral. Não se trata, portanto, de oportunismo ou afinidades contextuais, mas de necessidade estrutural de complementação de valores que viabilizam os processos sociais e econômicos concretos.

No caso da pandemia, a função do conservadorismo tem sido ainda mais decisiva. Ao recusar as medidas sanitárias recomendadas para controle da pandemia, especialmente o isolamento social mais amplo, Bolsonaro atendeu interesses econômicos de grupos que se fortaleceram em seu governo. O negacionismo científico, caracterizado por um aparente irracionalismo, era movido por interesses racionais bem concretos. Porém, mesmo Bolsonaro e sua equipe sabiam que o negacionismo não impediria um número alto de mortes. A responsabilidade por essas mortes precisaria, de qualquer maneira, ser atribuída a algum ente distinto do governo. Aqui, uma vez mais e, talvez, de forma ainda mais decisiva, a instituição família se fez presente ao viabilizar aquela que foi, na prática, a política de governo na pandemia: a privatização do cuidado e responsabilização individualfamiliar das mortes.

\section{Referências bibliográficas}

Alves, D. (2020). Reunião ministerial de 22 de abril. Brasília, DF. Disponível em: https://veja.abril.com.br/wp-content/uploads/2020/05/laudo-digitalizado 220520201218.pdf. Acessado em 1 de junho de 2021.

Araújo, E. (2019). '"O Brasil voltou' discurso do ministro das relações exteriores, embaixador Ernesto Araújo, na Heritage Foundation". 11 de setembro, Washington, DC. Disponível em: http://funag.gov.br/images/Nova politica externa/HeritageFoundation port.pdf. Acessado em 1 de junho de 2021

. (2019b). "Palestra do Ministro das Relações Exteriores, Embaixador Ernesto Araújo, no seminário da Fundação Alexandre de Gusmão sobre globalismo". 10 de Junho, Brasília. 
Disponível em: http://funag.gov.br/index.php/pt-br/2015-02-12-19-38-42/2942. Acessado em 1 de junho de 2021.

- (2020). Reunião ministerial de 22 de abril de 2020. Brasília, DF. Disponível em: https://veja.abril.com.br/wp-content/uploads/2020/05/laudo-digitalizado 220520201218.pdf.

Acessado em 1 de junho de 2021.

Braga Netto, W. Reunião ministerial de 22 de abril. Brasília, DF. Disponível em: https://veja.abril.com.br/wp-content/uploads/2020/05/laudo-digitalizado 220520201218.pdf. Acessado em 1 de junho de 2021.

Boito Jr., A. (2018). Reforma e crise política no Brasil. São Paulo, SP: Ed. Unesp; Campinas, SP: Ed. Unicamp.

Bolsonaro, J. (2019). “Discurso proferido na 74" Assembleia Geral da ONU”. 24 de Setembro. New York, NY. Disponível em: https://www1.folha.uol.com.br/mundo/2019/09/veja-a-integra-dodiscurso-de-bolsonaro-na-onu-com-checagens-e-contextualizacoes.shtml. Acessado em 1 de junho de 2021.

. (2020). Pronunciamento do presidente da República, Jair Bolsonaro. 22 de Março. Planalto [YouTube]. Disponível em: https://youtu.be/Vl DYb-XaAE. Acessado em 1 de junho de 2021.

(2020b). Reunião ministerial de 22 de abril. Brasília, DF. Disponível em: https://veja.abril.com.br/wp-content/uploads/2020/05/laudo-digitalizado 220520201218.pdf.

Acessado em 1 de junho de 2021.

Brown, W. (2006). "Neoliberalism, neoconservatism, and de-democratization". Political Theory, 34 (6). pp. $690-714$.

. (2019). In the ruins of neoliberalism: the rise of antidemocratic politics in the West. New York, NY: Columbia University Press.

Campos Neto, R. (2020). Reunião ministerial de 22 de abril. Brasília, DF. Disponível em: https://veja.abril.com.br/wp-content/uploads/2020/05/laudo-digitalizado 220520201218.pdf.

Acessado em 1 de junho de 2021.

Cavalcante, S. (2021). "A condução neofascista da pandemia de Covid-19 no Brasil: da purificação da vida à normalização da morte". Calidoscópio, 19, pp. 4-17.

Chade, J. (2019). "Brasil veta termo "gênero" em resoluções da ONU e cria mal-estar". 27 de junho. Blog Jamil Chade, UOL Notícias [online]. Disponível em: https:/jamilchade.blogosfera.uol.com.br/2019/06/27/brasil-veta-termo-genero-em-resolucoesda-onu-e-cria-mal-estar/. Acessado em 1 de junho de 2021.

Cooper, M. (2017). Family values: between neoliberalism and the new social conservatism. New York, NY: Zone Books.

Dardot, P. e Laval, C. (2016). A nova razão do mundo: ensaio sobre a sociedade neoliberal. São Paulo: Boitempo. 
DeBolle, Monica (2020). "Reflexões sobre 2021". Revista Quatro Cinco Um. 23 de dezembro [online]. Disponível em: https://www.quatrocincoum.com.br/br/colunas/rupturas/reflexoes-sobre-2021. Acessado em 1 de junho de 2021.

Fonseca, J. (2021). “Esquerda precisa superar jogo infantil sobre Bolsonaro e impeachment de Dilma". Folha de São Paulo, 16 de maio. Disponível em: https://www1.folha.uol.com.br/ilustrissima/2021/05/esquerda-precisa-superar-jogo-infantilsobre-bolsonaro-e-impeachment-de-dilma.shtml. Acessado em 1 de junho de 2021.

Friedman, M. (1962). Capitalism and freedom. Chicago, IL: University of Chicago Press.

Guedes, P. (2020). Reunião ministerial de 22 de abril. Brasília, DF. Disponível em:https://veja.abril.com.br/wp-content/uploads/2020/05/laudo-digitalizado 220520201218.pdf. Acessado em 1 de junho de 2021.

Guimarães, P. (2020). Reunião ministerial de 22 de abril. Brasília. Disponível em: https://veja.abril.com.br/wp-content/uploads/2020/05/laudo-digitalizado 220520201218.pdf.

Acessado em 1 de junho de 2021.

Hayek, F. (2011). The constitution of liberty: the definitive edition, [the collected works of F. A. Hayek]. Chicago, IL: University of Chicago Press.

Lacerda, M. B. (2019). O novo conservadorismo brasileiro. Porto Alegre: Zouk Editora.

Levitsky, S. e Ziblatt, D. (2018). Como as democracias morrem. São Paulo: Zahar.

Marinho, R. (2020). Reunião ministerial de 22 de abril. Brasília. Disponível em: https://veja.abril.com.br/wp-content/uploads/2020/05/laudo-digitalizado 220520201218.pdf. Acessado em 1 de junho de 2021.

Martins, F. G. (2019). "Globalismo: teoria da conspiração ou fenômeno político observável?". Palestra no Seminário "Globalismo", promovido pelo Ministério das Relações Exteriores (MRE) e a Fundação Alexandre de Gusmão (FUNAG), Brasília. Disponível em: https://www.dailymotion.com/video/x7vaf6j

Nicolau Netto, M., Cavalcante, S. (2019) e Chaguri, M. “O homem médio e o conservadorismo liberal no Brasil contemporâneo: o lugar da família". Paper do 43 Encontro Anual da Associação Nacional de Pós-Graduação e Pesquisa em Ciências Sociais.

Paranhos, T. (2019). Bolsonaro sobre liberdade econômica: "Tirar o Estado do cangote de quem produz". Metrópolis. 22 de setembro [online]. Disponível em: https://www.metropoles.com/brasil/politica-brasil/bolsonaro-sobre-liberdade-economica-tiraro-estado-do-cangote-de-quem-produz. Acessado em 1 de junho de 2021.

Seabra, C. e Garcia, D. (2021). “Bolsonaro multiplica por 10 número de militares no comando de estatais". Folha de São Paulo, 6 de março [online]. Disponível em: https://www1.folha.uol.com.br/mercado/2021/03/bolsonaro-multiplica-por-10-numero-demilitares-no-comando-de-estatais.shtml. Acessado em 1 de junho de 2021.

Serapião, F. e Seto, G. (2020). "Vida não tem 'valor infinito', diz presidente do Banco do Brasil ao criticar quarentenas por coronavírus". Folha de São Paulo, 26 de março [online]. Disponível em: 
https://www1.folha.uol.com.br/colunas/painel/2020/03/no-whatsapp-presidente-do-bb-diz-quevida-nao-tem-valor-infinito.shtml. Acessado em 1 de junho de 2021.

Salles, R. (2020). Reunião ministerial de 22 de abril. Brasília, DF. Disponível em: https://veja.abril.com.br/wp-content/uploads/2020/05/laudo-digitalizado 220520201218.pdf. Acessado em 1 de junho de 2021.

Singer, A. (2012). Os sentidos do lulismo. São Paulo, SP: Companhia das Letras. 